\title{
Influence of Obesity Surgery on Restless Leg Syndrome
}

\author{
Sabri Ozdas ${ }^{1}$ and Ramazan Ilyas Oner²
}

\begin{abstract}
Objective: To investigate whether restless leg syndrome (RLS) symptoms improved and treatment requirement decreased through weight loss on postoperative follow-ups of the patients who underwent laparoscopic sleave gastrectomy (LSG) due to obesity and who were started medical therapy due to RLS.

Study Design: A descriptive study.

Place and Duration of Study: General Surgery Outpatient Clinics of Research and Training Hospital of Medical School, Adiyaman, Turkey, from May 2014 to December 2017.

Methodology: A total of 14 patients who underwent LSG due to morbid obesity and who received medical treatment due to RLS were retrospectively included in the study. The improvement of the symptoms and no need for medical treatment were considered as treatment or recovery criterion. Those who were not diagnosed with RLS before the operation or who did not receive medical treatment due to RLS were excluded.

Results: The study subjects comprised 6 females (42.9\%) and 8 males (57.1\%). Mean BMI was $46.50 \pm 3.43 \mathrm{Kg} / \mathrm{m}^{2}$ before LSG and $28.28 \pm 2.26 \mathrm{Kg} / \mathrm{m}^{2}$ on months 12 after LSG. Mean BMI values 12 months after LSG were significantly reduced compared to preoperative $\mathrm{BMI}(\mathrm{p}=0.001)$. Out of the 14 patients who had been receiving medical therapy before LSG, 12 patients $(85.7 \%)$ had discontinued medical therapy 12 months after LSG. A statistically significant difference was detected between the number of the patients who were receiving medical therapy due to RLS on month 12 after LSG and the number of the patients who were receiving medical therapy before LSG $(p=0.001)$.

Conclusion: Treatment requirements of morbid obese patients who were receiving medical therapy due to RLS significantly decreased through weight loss following RLS.
\end{abstract}

Key Words: Obesity, Restless leg syndrome, Sleep disorders, Laparoscopic sleeve gastrectomy.

\section{INTRODUCTION}

Restless leg syndrome (RLS), which is a chronic neurosensory-motor disorder, is a disease which is usually accompanied by disturbing or unpleasant sensations, characterised by an irresistible impulse for moving the legs. This sensation which may be as a severe pain may temporarily relieve with movements.

Prevalence of RLS varies between $4 \%$ and $10 \%$ in the general population. ${ }^{1} \mathrm{RLS}$, which is characterised by delay in starting sleep, difficulty to maintain sleep, decreased total sleeping time and impairment in slow-wave sleep, leads to an impairment in quality of life. ${ }^{2}$ Depression, anxiety and pain disorders are common co-morbid conditions which accompany RLS. ${ }^{3}$ Diabetes, cardiovascular disease and stroke risk may also increase in RLS patients. ${ }^{4}$

While early-onset RLS (before 45 years) is usually idiopathic, ${ }^{5}$ secondary RLS (after 45 years) mainly occurs

\footnotetext{
1 Department of General Surgery, Research and Training Hospital of Medical School, Adiyaman, Turkey

2 Department of Internal Medicine, Faculty of Medicine, Adiyaman University, Adiyaman, Turkey

Correspondence: Dr. Ramazan Ilyas Oner, Department of Internal Medicine, Faculty of Medicine, Adiyaman University, Yunus Emre Mah, Sifa Cad, 02100 Adiyaman, Turkey E-mail: ilyasoner@hotmail.com

Received: July 31, 2018; Accepted: November 03, 2018
}

due to iron deficiency, pregnancy and end stage renal disease (ESRD). Although patho-physiology of RLS is not clear yet, it is considered to be associated with cerebral iron metabolism dysfunction, which leads to abnormal dopaminergic outcomes, 6,7 together with an underlying genetic predisposition. 1,6

Obesity is an important community health problem which is responsible for an important part of sleep-related complaints. ${ }^{8}$ It is directly related with sleep disorders like obstructive sleep apnea syndrome and insomnia. ${ }^{9}$ The association between RLS and obesity has been investigated in many studies as RLS is also a sleep disorder. RLS patients were reported to have higher BMI values compared to the patients without RLS. 10 RLS prevalence was reported to be higher in obese individuals compared to the non-obese. ${ }^{11}$

Similar changes in dopamine metabolism in RLS and obesity have shown a potential relationship between them. ${ }^{12,13}$ The factor like iron deficiency having an important role in etio-pathogenesis of RLS, ${ }^{6}$ the relationship between obesity and iron deficiency, 14 increase the importance of obesity as a risk factor for RLS.

Given the close relationship between obesity and RLS, the aim of this study was to investigate whether RLS symptoms improved and treatment requirement decreased through weight loss on postoperative followups of the patients who underwent LSG due to obesity and who were started medical therapy due to RLS. 


\section{METHODOLOGY}

A total of 14 patients out of 160 who were performed LSG due to morbid obesity at General Surgery Outpatient Clinics of Adiyaman Research and Training Hospital of Medical School between 1 May 2014 and 12 December 2017, whose BMI is $\geq 40$ and who were receiving medical therapy due to RLS, were retrospectively screened and included in the study. Patients included in the study were evaluated at regular intervals ( 3 months) for one year in the outpatient clinic. The biochemical parameters like Iron levels, iron binding capacity, Ferritin, hemoglobin $(\mathrm{Hgb})$ and vitamin $\mathrm{B} 12$ and $\mathrm{BMI}$ values of the patients were recorded before and after the operation of LSG during regular outpatient follow-ups. BMI values weight/height ${ }^{2}\left(\mathrm{Kg} / \mathrm{m}^{2}\right)$ were calculated and recorded. Ferritin and vitamin B12 values were calculated using Beckman Coulter Unicel DXL 800 Automated immuno-assay analyser device (USA) and hemogram values were analysed using Abbott CellDyne Ruby hematology analyser device.

The patients with morbid obesity who were diagnosed as RLS in the Neurology Outpatient Clinics before being operated for obesity were included in the study. These patients described an urge to move the legs caused by unpleasant and uncomfortable sensations. The complaints developed especially in the evening or night and were partially or fully relieved by movement. The improvement of the symptoms and no need for medical treatment were considered as treatment or recovery criterion. Those who were not diagnosed with RLS before the operation or who did not receive medical treatment due to RLS were excluded. Comorbid conditions were determined. The patients did not have heart failure, renal failure, peripheral neuropathy, pregnancy (for women), arterial insufficiency, spinal cord or cauda equine trauma, epilepsy. The patients did not have the family history of RLS.

Treatments used for RLS before LSG and on months 12 after LSG were recorded. The patients were administered oral iron replacement during 6 months after LSG, other vitamin replacements including B12 during 12 months after LSG. Local Ethics Committee approval was obtained prior to the study (2018/2-34 dated 03.20.2018).

To evaluate the assumption of normality in the data, the Kolmogorov-Smirnov test was used; and to describe the data, frequency (percent), mean $\pm \mathrm{SD}$, median and quartile were used. The analysis was conducted Chisquare test to analyse qualitative variables. The paired samples t-test and Wilcoxon signed ranks test were used to compare pre- and post-operative values of patient-related variables. Chi-square test was used to compare changes in patients' need for treatment before and after the operation. P-value less than 0.05 was considered as statistically significant. All statistical analyses were performed by SPSS software (version 21.0, Microsoft Co., Chicago, IL, USA).

\section{RESULTS}

Of the 14 morbid obese patients who were being followed up with diagnosis of RLS, 6 (42.9\%) were females and $8(57.1 \%)$ were males. The mean age of the patients was $40.50 \pm 7.60$ (minimum: 28 , maximum: 52 ) years. Mean preoperative BMI was $46.50 \pm 3.43 \mathrm{Kg} / \mathrm{m}^{2}$ (minimum: 42, maximum: 52). Mean BMI on postoperative month 12 was $28.28 \pm 2.26 \mathrm{Kg} / \mathrm{m} 2$ (minimum: 24, maximum: 32, Table I).

Fourteen patients were receiving medical therapy for RLS. Five patients received paroxetine; four patients received pregabalin; three patients recieved gabapentin, and one patient each received clonazepam and zoleplan. Comorbid conditions of the patients are summarised in Table II.

While 14 patients were receiving medications due to RLS before LSG, 12 patients (85.7\%) discontinued medications on month 12 after LSG. A statistically significant difference was detected between the patients who were receiving medications due to RLS on month

Table I: Values of RLS patients before surgery and at 12 months.

\begin{tabular}{lcc}
\hline & Mean \pm SD & $p$-value * \\
\hline B12 preoperation & $182.07 \pm 52.61$ & \\
B12 12 months & $307.07 \pm 107.82$ & $\mathrm{p}=0.001$ \\
BMI preoperation & $46.50 \pm 3.43$ & \\
BMl 12 months & $28.28 \pm 2.26$ & $\mathrm{p}=0.001$ \\
Hgb preoperation & $10.95 \pm 1.38$ & \\
Hgb 12 months & $15.57 \pm 1.12$ & $\mathrm{p}=0.001$ \\
\hline
\end{tabular}

RLS: Restless leg syndrome; BMI: Body mass index; Hgb: Hemoglobin. *Paired samples t-test.

Table II: Comorbidity of patients.

\begin{tabular}{lcc}
\hline & Mean \pm SD & p-value * \\
\hline AB & 2 & 14.3 \\
CPVI & 2 & 14.3 \\
DM+HT & 2 & 14.3 \\
DM+HT+CPVI+AB & 1 & 7.1 \\
DM+HT+KPVY+COPD & 1 & 7.1 \\
HT+CPVI & 3 & 21.4 \\
CPVI+AB & 1 & 7.1 \\
HT+CPVI+AB & 1 & 7.1 \\
No & 1 & 7.1 \\
\hline
\end{tabular}

AB: Asthma bronchiale; DM: Diabetes mellitus; CPVI: Chronic peripheral venous insufficiency, COPD: Chronic obstructive pulmonary disease; HT: Hipertension.

Table III: Cases of patients continuing medical treatment before and after LSG*.

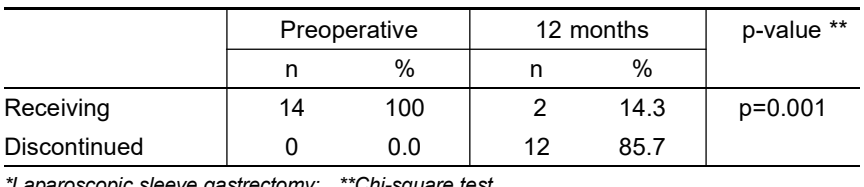

Table IV: Values of RLS patients before surgery and at 12 months.

\begin{tabular}{l|c|c|c}
\hline & Preoperation & 12 months & p-value $^{*}$ \\
\hline Ferritin & $18.85(11.27-33.13)$ & $184.77(138.97-232.45)$ & 0.001 \\
Iron & $92.5(44.75-117.25)$ & $160.5(136-174)$ & 0.001 \\
IBC & $242(191.75-360)$ & $226.5(189.75-354)$ & 0.975 \\
\hline
\end{tabular}

*Wilcoxon test, median (quartile).

RLS: Restless leg syndrome; IBC: Iron binding capacity. 
12 after LSG and the patients who were receiving medications before LSG $(p=0.001$, Table III).

The changes between iron levels, iron binding capacity, Ferritin, vitamin B12, hemoglobin ( $\mathrm{Hgb})$ and BMI before the operation and on month 12 after the operation; and significance levels are summarised in Tables I and IV. While iron level and ferritin were below normal values in 3 patients before LSG, they were normal in 11 patients. A significant alteration was not detected between iron levels, ferritin and $\mathrm{Hgb}$ values and $\mathrm{BMI}$ values before LSG and on month 12 after LSG $(p=0.844, p=0.575$ and $\mathrm{p}=0.423$, respectively).

\section{DISCUSSION}

This study has revealed that the requirement for medical therapy significantly decreased through losing weight after LSG in patients who were receiving medical therapy due to RLS and who were also morbid obese. A correlation was detected between the significant reduction in BMI values after LSG and the reduction in requirement for medications.

Gao et al. have revealed that RLS prevalence increased with increasing BMI in males and females in their cohort study. ${ }^{12}$ The authors have also reported that the increased prevalence of RLS in obese population was not associated with age, smoking status, anxiety score, anti-depressant use and some chronic diseases.

Similarly, Winkelman et al. have detected a significant association between RLS symptoms and elevated BMI in their cohort study conducted in USA.15 In another study, investigating the influence of obesity on RLS, the prevalence of RLS was found to significantly increase among the individuals whose $\mathrm{BMI}>30 \mathrm{Kg} / \mathrm{m}^{2}$ compared to the individuals whose $\mathrm{BMI}<30 \mathrm{Kg} / \mathrm{m}^{2} .11$ Supporting these studies, Yildiz et al. have reported that obesity and high BMI values are associated with RLS development. 16 However, some other studies propose that there is not an association between obesity and RLS. 17,18

As mentioned above, while an ample amount of studies are available reporting that obesity is an important risk factor for RLS development, 9,19 to the best of authors' knowledge, no studies are available in literature investigating the association between weight loss and improvement in RLS symptoms and reduction in medication requirements. Detecting a reduction in RLS symptoms together with significant weight loss after LSG enhances the importance of this study.

Obesity and RLS are diseases related with dopamine hypo-function in central nervous system. ${ }^{12}$ A study has reported that dopamine $D 2 / 3 R$ receptor binding reduced in the obese compared to the non-obese. ${ }^{13}$ Low D2 dopamine receptor levels observed in obese rats in animal tests also support these opinions. ${ }^{20}$ This reduction in receptor count may be accepted as one of the causes for obesity-related RLS development.21 However, the studies investigating the changes (reduction or elevation) in these receptors following bariatric surgery report conflicting results. 22 It is seen that further studies are required due to the small patient populations in those studies. Besides, the alteration in receptor count resulting from weight loss and the alterations in clinical signs of RLS could influence treatment approaches.

Iron deficiency is an important factor for etio-pathogenesis of RLS. 6 The influences of iron replacement on RLS symptoms have been evaluated and RLS symptoms were seen to be able to be completely eliminated through iron therapy. ${ }^{7}$ Even a correlation was detected between the severity of RLS and reduced ferritin levels and this correlation was seen to continue after replacement therapy even if ferritin levels are within normal ranges. ${ }^{1}$ Iron replacement was observed to significantly improve RLS symptoms, particularly in patients whose pre-treatment ferritin level is $<45 \mathrm{mcg} / \mathrm{L} .23$

The studies investigating the association between iron deficiency and obesity present conflicting results. In a meta-analysis in China, obesity was detected to have a significant effect on iron deficiency. ${ }^{14}$ Manios et al. have also detected that obesity has an important relationship with obesity and iron deficiency and iron deficiency anemia in children and adolescents. ${ }^{24}$ On the contrary to these studies, reports are available stating that although iron deficiency anemia is common among the obese, a significant association is not present between obesity and iron deficiency in multi-variable logistic regression analysis. ${ }^{25}$ In this patient group, while iron, ferritin, $\mathrm{Hgb}$ values significantly increased on month 12 after LSG compared to preoperative values, BMI values significantly reduced. However a significant correlation was not found between $\mathrm{BMI}$ and iron, ferritin and $\mathrm{Hgb}$ values.

\section{CONCLUSION}

Biologic changes which could result from obesity and carry risk for RLS development (like iron and ferritin) improve with losing weight or replacement therapy, we could not detect a significant correlation with BMI. However the correlation between the regression in RLS symptoms and BMI alteration has shown that obesity treatment could be an effective factor on RLS symptoms. Recognising obesity-related diseases is of great importance as obesity is a modifiable community health problem. Further studies are required for investigation of the underlying mechanisms of the potential roles of obesity in RLS and for assessment of the influence of weight loss on symptoms.

\section{REFERENCES}

1. Garcia-Borreguero D, Odin P, Schwarz C. Restless legs syndrome: An overview of the current understanding and management. Acta Neurol Scand 2004; 109:303-17. 
2. Stiasny K, Wetter TC, Trenkwalder C, Oertela WH. Restless legs syndrome and its treatment by dopamine agonists. Parkinsonism Relat Disord 2001; 7:21-5.

3. Becker PM, Novak M. Diagnosis, comorbidities, and management of restless legs syndrome. Curr Med Res Opin 2014; 30: 1441-60.

4. Innes KE, Kit T, Agarwal P. Restless legs syndrome and conditions associated with metabolic dysregulation, sympathoadrenal dysfunction, and cardiovascular disease risk: A systematic review. Sleep Med Rev 2012; 16:309-39.

5. Allen RP, Earley CJ. Defining the phenotype of the restless legs syndrome (RLS) using age-of-symptom-onset. Sleep Med 2000; 1:11-9.

6. Dauvilliers $Y$, Winkelmann J. Restless legs syndrome: Update on pathogenesis. Curr Opin Pulm Med 2013; 19:594-600.

7. Allen RP, Earley CJ. The role of iron in restless legs syndrome. Mov Disord 2007; 22:440-8.

8. Grandner MA, Patel NP, Perlis ML, Gehrman PR, Xie D, Sha D, et al. Obesity, diabetes, and exercise associated with sleeprelated complaints in the American population. Z Gesundh Wiss 2011; 19:463-74.

9. Hargens TA, Kaleth AS, Edwards ES, Butner KL. Association between sleep disorders, obesity, and exercise: A review. Nat Sci Sleep 2013; 5:27-35.

10. Schlesinger I, Erikh I, Avizohar O, Sprecher E, Yarnitsky D. Cardiovascular risk factors in restless legs syndrome. Mov Disord 2009; 24:1587-92.

11. Mustafa M, Erokwu N, Ebose I, Strohl K. Sleep problems and the risk for sleep disorders in an outpatient veteran population. Sleep Breath 2005; 9:57-63.

12. Gao X, Schwarzschild MA, Wang $H$, Ascherio A. Obesity and restless legs syndrome in men and women. Neurology 2009; 72:1255-61.

13. De Weijer BA, Van De Giessen E, Janssen I, Berends FJ, Laar AVD, Ackermans MT, et al. Striatal dopamine receptor binding in morbidly obese women before and after gastric bypass surgery and its relationship with insulin sensitivity. Diabetologia 2014; 57:1078-80.

14. Zhao L, Zhang X, Shen Y, Fang X, Wang Y, Wang F. Obesity and iron deficiency: a quantitative meta-analysis. Obes Rev 2015; 16:1081-93.

15. Winkelman JW, Finn L, Young T. Prevalence and correlates of restless legs syndrome symptoms in the Wisconsin Sleep Cohort. Sleep Med 2006; 7:545-52.

16. Yildiz D, Buyukkoyuncu N, Kilic AK, Cander S, Yildiz A, Gunes A, et al. Obesity: A possible risk factor for restless legs syndrome. Neurol Res 2017; 39:1044-8.

17. Benediktsdottir B, Janson C, Lindberg E, Arnardóttir ES, Olafsson I, Cook E, et al. Prevalence of restless legs syndrome among adults in Iceland and Sweden: Lung function, comorbidity, ferritin, biomarkers and quality of life. Sleep Med 2010; 11:1043-8.

18. Berger K, Luedemann J, Trenkwalder C, John U, Kessler C. Sex and the risk of restless legs syndrome in the general population. Arch Intern Med 2004; 164:196-202.

19. Szentkirályi A, Völzke H, Hoffmann W, Happe S, Berger K. A time sequence analysis of the relationship between cardiovascular risk factors, vascular diseases and restless legs syndrome in the general population. J Sleep Res 2013; 22: 434-42.

20. Huang XF, Zavitsanou K, Huang X, Yu Y, Wang H, Chen F, et al. Dopamine transporter and $\mathrm{D} 2$ receptor binding densities in mice prone or resistant to chronic high fat diet-induced obesity. Behav Brain Res 2006; 175:415-9.

21. Wang GJ, Volkow ND, Logan J, Pappas NR, Wong CT, Zhu W, et al. Brain dopamine and obesity. Lancet 2001; 357:354-7.

22. Steele KE, Prokopowicz GP, Schweitzer MA, Magunsuon TH, Lidor $\mathrm{AO}$, Kuwabawa $\mathrm{H}$, et al. Alterations of central dopamine receptors before and after gastric bypass surgery. Obes Surg 2010; 20:369-74.

23. O'Keeffe ST, Noel J, Lavan JN. Restless legs syndrome in the elderly. Postgrad Med J 1993; 69:701-13.

24. Manios Y, Moschonis G, Chrousos GP, Lionis C, Mougios V, Kantilafti $\mathrm{M}$, et al. The double burden of obesity and iron deficiency on children and adolescents in Greece: The healthy growth study. J Hum Nutr Diet 2013; 26:470-8.

25. Arshad M, Jaberian S, Pazouki A, Riazi S, Rangraz MA, Mokhber S. Iron deficiency anemia and megaloblastic anemia in obese patients. Rom J Intern Med 2017; 55:3-7. 